\title{
Sucessão em empresas familiares: características dos estudos e lacunas de pesquisa
}

Djeimi Angela Leonhardt Neske ${ }^{1}$

Ivano Ribeiro ${ }^{1}$

Sandra Mara Stocker Lago ${ }^{1}$

${ }^{1}$ Universidade Estadual do Oeste do Paraná 


\section{SUCESSÃO EM EMPRESAS FAMILIARES: CARACTERÍSTICAS DOS ESTUDOS E LACUNAS DE PESQUISA}

Resumo: Este artigo identificou as principais características dos estudos sobre sucessão em empresas familiares com vistas na verificação de possíveis lacunas de pesquisa. A partir de uma amostra final que foi composta por três teses, 30 dissertações e 37 artigos publicados entre os anos de 2007 até 2017 se levantou: o ano das publicações, instituições mais proeminentes, metodologias utilizadas, temáticas centrais, principais autores e periódicos mais recorrentes. A principal contribuição é a elaboração de uma agenda de pesquisa pautada nas principais lacunas de conhecimento que foram identificadas.

Palavras-chave: Estratégia, Tomada de decisão estratégica. Governança.

\section{Introdução}

A sucessão, deve ser compreendida como um processo contínuo, que demanda de tempo para que ocorra a mudança adequada nos papéis que as pessoas exercem (Gersick, Daves, Hampton \& Lansberg, 2006; Harvey, 1995). Neste sentido, quando as empresas elaboram um adequado planejamento para este processo, podem evitar desgastes desnecessários, além de estarem mais aptas para enfrentarem possíveis dificuldades, alavancando deste modo a longevidade do negócio (Meira Teixeira \& Carvalhal, 2013).

Historicamente, as pesquisas têm demonstrado que poucas empresas sobrevivem à gestão de seu fundador. Tal fato, pode ocorrer devido ao entendimento inadequado dos gestores em relação ao processo sucessório, que o percebe como um evento isolado, tratandoo como simples transferência de poder (CANÇADO, et al., 2013). Neto e Moreira Jr (2010) também apontam que um elevado número de empresas sucumbe na sucessão de seus gestores, devido especialmente à falta de um planejamento específico para este período.

Planejar antecipadamente, aumentam as possibilidades de que a sucessão ocorra de forma saudável e pacífica podendo se tornar um momento benéfico para a organização (FERRAZZA, 2010). Neste sentido, a Governança Corporativa, por meio de Conselhos de Administração e Família, pode aliar as melhores práticas estabelecendo regulamentos benéficos para a organização (ROTH; TISSOT; GONÇALVES, 2017).

A sucessão familiar tem sido amplamente discutida no meio acadêmico. Os estudos apresentam diferentes contextos específicos. O processo em si é abordado em revisões de literatura (SANTOS et al., 2017; BORGES; DE BRITO; DE LIMA; CASTRO, 2016; BORGES; LESCURA; OLIVEIRA, 2012; PAIVA; OLIVEIRA; MELO, 2008). No entanto, nenhuma dessas revisões contempla a revisão de teses e dissertações.

Sendo assim, o objetivo geral deste estudo é analisar as publicações científicas brasileiras acerca da sucessão em empresas familiares, no período de 2007 a 2017. Destarte, a

\section{Organizadores:}

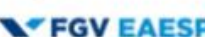

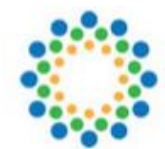

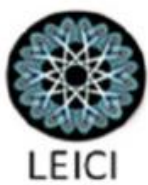


questão da pesquisa investiga: Quais são as características dos estudos que tratam da sucessão familiar e quais as principais lacunas de pesquisa existentes?

A escolha do tema para a pesquisa é justificada pelo fato de que a sucessão impacta direta e fortemente no aspecto competitivo e de sobrevivência das empresas familiares. Deste modo, elaborou-se o levantamento de teses, dissertações e artigos científicos que tratassem da temática no período de publicação de 2007 até 2017. Os principais resultados, demonstram a que existe carência de estudos utilizando a abordagem quantitativa e que existem lacunas de conhecimento, principalmente quando se trata de processo sucessório, governança, gênero, gestão e profissionalização. A partir destas observações presenta-se uma agenda de pesquisa que visa auxiliar no direcionamento de novas pesquisas nestas temáticas.

\section{Empresa familiar e sucessão}

A constante pesquisa acerca de empresas familiares é relevante pela representatividade que as mesmas exercem na economia mundial e, por conseguinte, para a manutenção e desenvolvimento da sociedade como um todo (DE MASSIS; CHUA; CHRISMAN, 2008; PAPA; LUZ, 2008; OLIVEIRA, et al., 2014; SANTOS et al., 2017).

Por mais que o tema seja estudado, existem divergências para a definição de um conceito acerca da empresa familiar e ela ocorre tanto no âmbito teórico quanto empírico (HANDLER, 1989; CHUA; CHRISMAN; SHARMA, 1999). De acordo com Handller (1989), a maior parte dos pesquisadores entende o envolvimento familiar acerca da propriedade e da gestão. O mesmo autor, apresenta ainda a seguinte definição "uma organização cujas principais decisões e planos operacionais para a sucessão de liderança são influenciados por membros da família que atuam na administração ou no conselho" (HANDLER, 1989, p. 262).

Churchill e Hatten (1997) também inserem à luz da discussão, a existência de um sucessor familiar. Quando investigado o conceito de empresa familiar, há de acordo com os próprios empresários, divergência sobre a definição. Alguns compreendem que se trata de empresa familiar somente quando todos os envolvidos no negócio são da família, enquanto isso, para membros familiares que possuem o negócio, mas não atuam nele, insistem que se trata de uma empresa familiar, ainda que ocorra uma gestão profissional (CHUA; CHRISMAN; SHARMA, 1999).

Corroborando com Churchill e Hatten (1997), no sentido de incluir a sucessão familiar, Papa e da Luz (2008), entendem que três grandes vertentes são abarcadas: nível de propriedade, no qual o controle majoritário do capital está nas mãos da família; nível de gestão, em que os membros da família ocupam os principais cargos da empresa; e o nível de sucessão, neste, a segunda geração passa a ocupar continuamente os cargos que vão sendo deixados pelos parentes que passam a não atuar mais no controle do negócio.

Destarte, cabe apresentar a definição de empresa familiar proposta por Chua, Chrisman e Sharma (1999, p.25)

"um negócio governado e/ou gerenciado com a intenção de moldar e perseguir a visão do negócio de uma coalizão dominante controlada por membros da mesma

\section{Organizadores:}

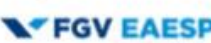

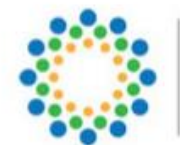

ANEGEPE

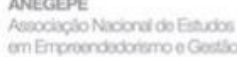
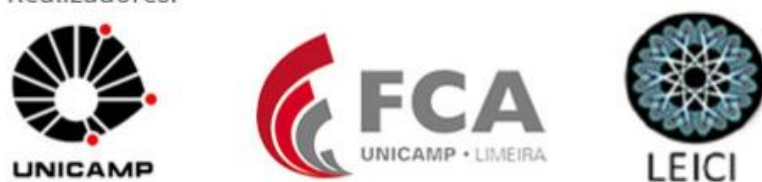
família ou um pequeno número de famílias de uma forma que é potencialmente sustentável entre as gerações da família ou famílias."

Partindo da verificação de que a temática da sucessão está inserida na própria definição de empresa familiar, ou seja, que para ser considerada de fato uma empresa familiar, a mesma deve estar ao menos na segunda geração, este aspecto, aponta indícios da sua relevância em âmbito das empresas familiares. Sendo assim, um dos temas mais abordados a respeito das empresas familiares, refere-se a sucessão destas, uma das razões para que isto ocorra advém por esse aspecto ser considerado por diversos autores uma das situações mais críticas e complexas enfrentadas pelas empresas familiares (DE MASSIS; CHUA; CHRISMAN, 2008; MEIRA TEIXEIRA; CARVALHAL, 2013).

Algo que pode dificultar o processo sucessório é a proximidade entre os campos familiar e empresarial, pois diferentes interesses podem gerar tensões e conflitos que precisam ser administrados corretamente, para não afetar a empresa (BRITO; SILVA; MUNIZ, 2010). No entanto, é necessário perceber que a formação, experiência e competências adequadas para o provável gestor, demandam de um longo tempo, pois deve ser construído e deve ser entendido pela família como um processo à longo prazo (OLIVEIRA; ALBUQUERQUE; PERREIRA, 2012).

Diversos estudiosos e consultores do assunto apontam que a sucessão e as consequências dela advindas, tornam-se um momento decisivo para a sobrevivência de pequenas e médias empresas, frente a um mercado constantemente mais exigente e competitivo (LEONE, 2008). Sob uma perspectiva estratégica, a continuidade dos negócios sob domínio da família empresária, depende da forma como o processo de sucessão acontece (BORGES; LIMA, 2009).

Vários fatores compõe a sucessão, não se tratando, portanto, de um processo isolado, no qual um líder simplesmente passa sua reponsabilidade para um novo líder, trata-se assim, de um processo que necessita de tempo, ainda quando ocorre de forma inesperada (evento dramático, doença ou morte súbita), casos em que há rápida necessidade de mudança nos papéis e funções desempenhados pelas pessoas (GERSICK et al., 2006).

Considerando a sucessão como um processo de longo prazo, empresas que elaboram um planejamento para esse processo evitam problemas e podem estar melhor preparadas para as dificuldades, aumentando as possibilidades de sobrevivência do negócio (MEIRA TEIXEIRA; CARVALHAL, 2013).

\section{Metodologia e Desenvolvimento}

Para atender o objetivo proposto neste estudo, realizou-se levantamento sistemático da produção científica acerca do tema "sucessão em empresas familiares". A busca de trabalhos inclui teses e dissertações defendidas em Programas de Stricto Sensu e artigos científicos e relatos técnicos publicados em periódicos avaliados nos estratos de A2 até B3 do sistema de avaliação da Coordenação de Aperfeiçoamento de Pessoal de Nível Superior (CAPES). O período de busca em todos os casos foi delimitado nos anos de 2007 a 2017.
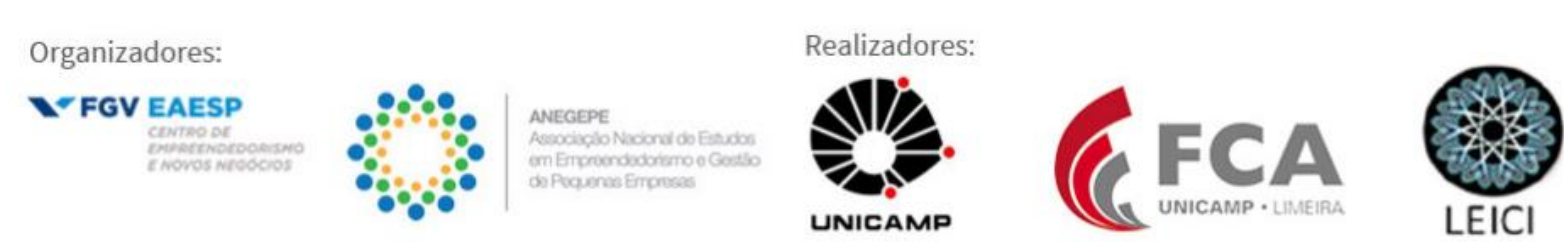
A primeira etapa consistiu em realizar testes para avaliar o retorno e definir a palavrachave adequada para busca, optando-se por utilizar aquela que apresentasse maior retorno. A palavra-chave de busca foi "sucessão", utilizada em português para busca de teses e dissertações, no portal da CAPES e na Biblioteca Digital Brasileira de Teses e Dissertações do Instituto Brasileiro de Informação em Ciência e Tecnologia (BDTD - IBICT) e o termo em inglês succession, utilizado para a busca nos periódicos.

A segunda etapa decorreu na busca efetiva de teses e dissertações realizada no catalogo de teses e dissertações da CAPES no dia 13/10/217 e no BDTD - IBICT, em 16/10/2017. O resultado final das buscas é composto de 3 teses e 30 dissertações.

Os resultados podem ser assim descritos. Na CAPES: resultado inicial $=3.607$; Filtro 1: Período 2007-2017 = 2.339; Filtro 2: Administração/Sucessão, nome programa $=105$; Critério de exclusão 1: Profissionalizante $=-11$; Critério de exclusão 2: Leitura título $=-50$; Critério de exclusão 3: Leitura resumo $=-12$; Critério de exclusão 4: Não localizados $=-3$. Resultado final da base $=29$.

Na IBICT: resultado inicial $=2.055$; Filtro 1: Período 2007-2017 $=1.555$; Filtro 2: Administração/Sucessão, assunto $=40 ;$ Critério de exclusão 1: Leitura título $=-22$; Critério de exclusão 2: Leitura resumo $=-11$; Critério de exclusão 3: Não localizados $=-1$. Resultado final da base $=6$. O resultado geral, 35, exclusão de repetidos: -2 . Resultado final $=33$.

A terceira etapa, foi a busca por artigos científico e relatos técnicos. Para a seleção dos periódicos que seriam utilizados, teve-se por base os periódicos apresentados na Tabela 3, no estudo de Santos et al. (2017), visto que este estudo se trata de uma revisão e apresenta os resultados dos periódicos mais relevantes para área. A busca efetiva ocorreu por meio do ISSN dos periódicos utilizando o software Publish or Perish 6 para a busca.

O resultado é composto integralmente de artigos científicos sendo que nenhum relato técnico acerca do assunto foi encontrado. Os detalhes do levantamento nos periódicos foram: termo de busca $=$ succession; período: 2007 até $2017=184$; critério de exclusão 1: duplicados $=-40$; critério de exclusão 2: leitura título $=-89$; critério de exclusão 3 : leitura resumo $=-18$; resultado final $=37$. A data da busca, os periódicos pesquisados e seus respectivos resultados, são apresentados no Quadro 1. O resultado final compõe a amostra do estudo.

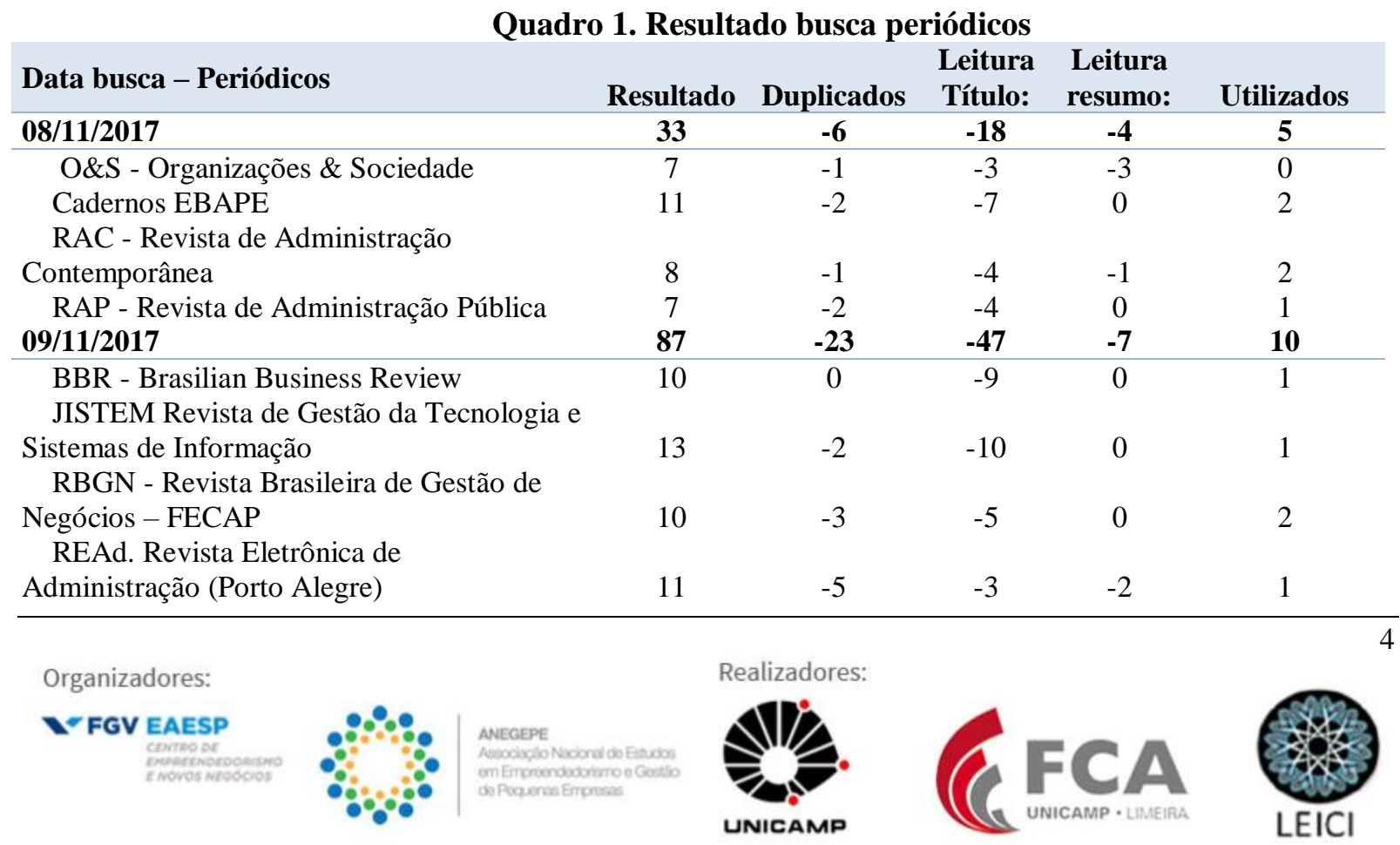




\begin{tabular}{|c|c|c|c|c|c|}
\hline Data busca - Periódicos & Resultado & Duplicados & $\begin{array}{l}\text { Leitura } \\
\text { Título: }\end{array}$ & $\begin{array}{l}\text { Leitura } \\
\text { resumo: }\end{array}$ & Utilizados \\
\hline REBRAE - Revista Brasileira de Estratégia & 9 & 0 & -6 & -2 & 1 \\
\hline Revista brasileira Est. Pop., Rebep & 7 & 0 & -5 & -2 & 0 \\
\hline $\begin{array}{l}\text { Revista Contabilidade \& Finanças - USP } \\
\text { REVISTA DE ADMINISTRAÇÃO }\end{array}$ & 10 & -5 & -4 & 0 & 1 \\
\hline MACKENZIE - RAM & 17 & -8 & -5 & -1 & 3 \\
\hline $16 / 11 / 2017$ & 36 & -9 & -12 & -3 & 12 \\
\hline $\begin{array}{l}\text { ALCANCE (UNIVALI) } \\
\text { BASE - Revista de Administração e }\end{array}$ & 5 & 0 & -1 & -1 & 3 \\
\hline $\begin{array}{l}\text { Contabilidade da Unisinos } \\
\text { Contextus - Revista Contemporânea de }\end{array}$ & 5 & 0 & -4 & 0 & 1 \\
\hline $\begin{array}{l}\text { Economia e Gestão } \\
\text { FACES: REVISTA DE }\end{array}$ & 5 & -2 & -1 & -1 & 1 \\
\hline $\begin{array}{l}\text { ADMINISTRAÇÃO (BELO HORIZONTE. } \\
\text { ONLINE) } \\
\text { REA. REVISTA ELETRÔNICA DE }\end{array}$ & 4 & -1 & 0 & -1 & 2 \\
\hline $\begin{array}{l}\text { ADMINISTRAÇÃO } \\
\text { REVISTA DE ADMINISTRAÇÃO DA }\end{array}$ & 1 & 0 & 0 & 0 & 1 \\
\hline UFSM - REA & 2 & -1 & 0 & 0 & 1 \\
\hline $\begin{array}{l}\text { Revista de Administração da UNIMEP } \\
\text { Revista de Ciências da Administração - }\end{array}$ & 5 & -2 & -2 & 0 & 1 \\
\hline $\begin{array}{l}\text { RCA } \\
\text { REVISTA IBERO-AMERICANA DE }\end{array}$ & 1 & 0 & 0 & 0 & 1 \\
\hline ESTRATÉGIA - RIAE & 8 & -3 & -4 & 0 & 1 \\
\hline $18 / 11 / 2017$ & 1 & $\mathbf{0}$ & $\mathbf{0}$ & $\mathbf{0}$ & 1 \\
\hline REVISTA ELETRÔNICA DE & & & & & \\
\hline ESTRATÉGIA E NEGÓCIOS & 1 & 0 & 0 & 0 & 1 \\
\hline $19 / 11 / 2017$ & 27 & -2 & -12 & -4 & 9 \\
\hline Gestão \& Planejamento, Salvador & 5 & 0 & -2 & 0 & 3 \\
\hline REGE REVISTA DE GESTAO & 2 & 0 & -1 & 0 & 1 \\
\hline REVISTA DE ADMINISTRACAO IMED & 2 & 0 & -1 & 0 & 1 \\
\hline Revista de Negócios - FURB & 2 & 0 & 0 & -1 & 1 \\
\hline Revista Economia e Gestão - E\&G & 6 & 0 & -5 & 0 & 1 \\
\hline Revista eletrônica Gestão e Sociedade & 3 & 0 & -2 & 0 & 1 \\
\hline Teoria e Prática em Administração - UFPB & 7 & -2 & -1 & -3 & 1 \\
\hline Total Geral & 184 & -40 & -89 & -18 & 37 \\
\hline
\end{tabular}

Fonte: Elaborado pelos autores, 2017.

Os resultados das buscas, foram tabulados em duas planilhas Excel, para auxiliar na pré-análise dos dados e posteriormente na tabulação e cruzamento dos dados. Na planilha das teses e dissertações foram detalhados os seguintes itens: número do trabalho; base (CAPES ou BDTD - IBICT); título, nome do programa; instituição; área de concentração; linha de pesquisa; mestrado/doutorado; ano de defesa; autor; origem do autor (formação até a publicação); classificação de tema central da tese/dissertação; métodos; resultados; sugestões de trabalhos futuros; observações; citação APA; citação ABNT - NBR 6023; palavras-chave.

Já a planilha dos artigos, contou com os itens: número do artigo; título revista; ISSN; classificação (estrato) CAPES; ano publicação; link acesso; autor 1, 2, 3, 4, 5 e 6; origem do autor 1, 2, 3, 4, 5 e 6; classificação do tema central do artigo; palavra-chave 1, 2, 3 e 4; objetivo; métodos; resultados; sugestões de trabalhos futuros; observações.

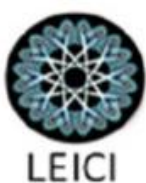


Para análise dos trabalhos selecionados, utilizou-se análise de conteúdo (BARDIN, 2010), visando uma exploração e conhecimento mais aprofundado acerca do tema. Tais análises são apresentadas nas próximas seções.

\section{Resultados}

\subsection{Teses e Dissertações}

A amostra final de teses e dissertações é composta por 3 teses e 30 dissertações. A primeira análise, foi em relação aos anos de defesa e publicações. Pode-se observar de acordo com esse resultado que no período selecionado o número de pesquisas não foi constante. Prevalecendo o ano de 2015 com o maior número de publicações, sendo destas, 2 teses e 5 dissertações, seguido do ano de 2009 com o total de 7 dissertações

Foram analisadas também, as instituições nas quais os estudos foram realizados. A FGV do Rio de Janeiro é a instituição com o maior número de publicações acerca da sucessão, no entanto, quando considerado o Estado de origem dessas instituições, Minas Gerais e São Paulo, contemplam o maior número de estudos, sendo 10 para cada Estado. Ponderando que a maior parte dos trabalhos consiste em estudos de casos, pode-se dizer que há maior concentração de empresas investigadas acerca da temática da sucessão familiar nos dois estados identificados.

Quanto a metodologia utilizada nas teses e dissertações, cabe ressaltar que nem todos os aspectos metodológicos estavam explícitos, incumbindo aos autores a cuidadosa leitura para posterior classificação, sendo utilizado como parâmetro aquela que prevalecesse em cada um dos aspectos de acordo com Gil (2007). Os resultados podem ser visualizados no Quadro2.

\section{Quadro 2. Metodologia utilizada nas teses e dissertações}

\begin{tabular}{l|l|c}
\hline Abordagem & Qualitativa & 33 \\
\hline \multirow{2}{*}{ Natureza } & Básica & 2 \\
\cline { 2 - 3 } & Aplicada & 31 \\
\hline Objetivos & Exploratória & 33 \\
\hline \multirow{4}{*}{ Procedimentos } & Estudo de caso & 16 \\
\cline { 2 - 3 } & Estudo de casos múltiplos & 1 \\
\cline { 2 - 3 } & Bibliográfica & 1 \\
\cline { 2 - 3 } & Ground Theory & 1 \\
\hline
\end{tabular}

Fonte: Elaborado pelos autores, 2017.

Quanto a temática central abordada nas teses e dissertações, todas versam acerca da sucessão. Algumas, abordam apenas a temática geral acerca do processo sucessório, outras, abordam além do processo sucessório, algum item mais específico inerente ao processo conforme Quadro 3. 


\begin{tabular}{l|l}
\multicolumn{2}{c}{ Quadro 3. Temática central abordada nas teses e dissertações } \\
\hline Temática central & Autores \\
\hline Competências gerenciais (sucessor) & (MATTOS, 2014) \\
\hline Conflitos & (TRENTIN, 2010) \\
\hline Conhecimento organizacional & (ORCY, 2015) \\
\hline Desafios & (GIMENES, 2015; SOARES, 2013; VIEIRA, 2008) \\
\hline Dificuldades & (DE LIMA, 2016; PESKER, 2013) \\
\hline Estrutura de carreira (sucessor) & (FERREIRA, 2015) \\
\hline Fatores Críticos & (FUNATSU, 2008) \\
\hline Formação do sucessor & (MAMEDE, 2015) \\
\hline Gênero & (ELOI, 2014; OLIVEIRA, 2008) \\
\hline Gestão & (COELHO, 2013; MORAES FILHO, 2009) \\
\hline Governança & (FREITAS, 2015) \\
\hline Interferência líderes & (MERHI, 2009) \\
\hline Legitimidade/Identificação sucessor & (MARTINS, 2013; OHTSUKI, 2013; CRUZ, 2012) \\
\hline Maturidade & (FERRAZZA, 2010) \\
\hline Mito fundador & (PEREIRA, 2010) \\
\hline Oportunidades & (PESKER, 2013) \\
\hline Planejamento & (NISHITSUJI, 2009) \\
\hline & (DUTRA, 2015; FERREIRA, 2015; TESTON, 2014; COELHO, \\
Processo sucessório & 2013; PERREIRA, 2010; BORGES, 2009; NISHITSUJI, 2009; \\
\hline Profissionalização & CARNEIRO FILHO, 2008; FUNATSU, 2008; VIEIRA, 2008) \\
\hline Relações interpessoais & (PEREIRA, 2010) \\
\hline Sucessão após 2 ${ }^{a}$ geração & (MOREIRA, 2009) \\
\hline
\end{tabular}

Fonte: Elaborado pelos autores, 2017.

As palavras-chave consistem em levar o leitor até o estudo, são elas que remetem às ideias principais que serão tratadas, destarte, servem de referência inclusive para pesquisas futuras. Nas teses e dissertações foram identificadas 125 palavras-chave. As principais são: Sucessão (24) + Processo Sucessório (9) + Sucessão familiar (1), totalizando 34 acerca da sucessão em si; Empresa familiar (27); Profissionalização (6); Gestão (4); Governança (1) + Governança corporativa (3).

\subsection{Artigos}

Os artigos selecionados, estão distribuídos em periódicos com diferentes estratos Qualis, tendo sido ao total: 9 em A2; 11 em B1; 14 em B2; 3 em B3. O maior número de publicações em periódicos com melhores estratos, remetem confiabilidade as pesquisas que tem sido realizada acerca da sucessão familiar. Os periódicos com maior número de publicação acerca do assunto são apresentados no Quadro 4. 
Quadro 4: Resultado periódicos

RAC

Cadernos EBAPE

RBGN - FECAP

RAM - Revista De Administração Mackenzie ALCANCE (UNIVALI)

Gestão \& Planejamento, Salvador

FACES: Revista de Administração (Belo

Horizonte. Online)

Com apenas 1 artigo

$\begin{array}{cc}\text { ISSN } & \text { Quali } \\ 1982-7849 & \text { A2 } \\ 1679-3951 & \text { A2 } \\ 1806-4892 & \text { A2 } \\ 1678-6971 & \text { B1 } \\ 1413-2591 & \text { B2 } \\ 2178-8030 & \text { B2 } \\ 1517-8900 & \text { B2 }\end{array}$

$1517-8900 \quad$ B2
Frequência absoluta

A2 2

A2 2

A2 2

B1 3

B2 3

3

2

20

Total

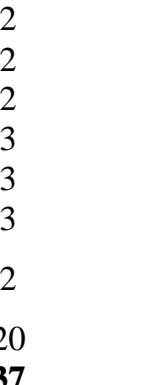

Fonte: Elaborado pelos autores, 2017.

A publicação dos artigos, ocorreu de forma mais regular ao longo dos anos com destaque para os anos de 2008 e 2013, com 5 publicações em cada um. A média foi de 3.7 artigos por ano.

A variedade entre os autores é vasta, totalizando 105, tendo sido a grande maioria responsável pela publicação de apenas um artigo. Janete Lara de Oliveira, consta como autora em 4 artigos, no entanto, há outros três autores "Oliveira" que aparecem com apenas um artigo publicado, fato que em uma pesquisa mais superficial pode causar equívocos. Juvêncio Braga de Lima também consta como autor em 4 artigos e Rafael Diogo Pereira, em 3. Os demais autores são responsáveis por uma ou duas publicações.

Da mesma forma que ocorreu com as teses e dissertações, a metodologia utilizada nos artigos também foi analisada seguindo os parâmetros recomendados por Gil (2007)

\section{Quadro 5. Metodologia utilizada nos artigos}

\begin{tabular}{l|l|c}
\hline \multirow{4}{*}{ Abordagem } & Qualitativa & 29 \\
\cline { 2 - 3 } & Quantitativa & 2 \\
\cline { 2 - 3 } \multirow{2}{*}{ Natureza } & Qualitativa e Quantitativa (Mista) & 6 \\
\hline \multirow{2}{*}{ Objetivos } & Básica & 33 \\
\cline { 2 - 3 } & Aplicada & 36 \\
\hline \multirow{5}{*}{ Procedimentos } & Exploratória & 1 \\
\cline { 2 - 3 } & Descritiva & 20 \\
\hline & Estudo de caso & 2 \\
\cline { 2 - 3 } & Estudo de casos múltiplos & 1 \\
\cline { 2 - 3 } & Bibliográfica & 1 \\
\cline { 2 - 3 } & Bibliométrica & 1 \\
\cline { 2 - 3 } & Metaestudo & 2 \\
\cline { 2 - 3 } & Survey & 3 \\
\hline
\end{tabular}

Fonte: Elaborado pelos autores, 2017.

As temáticas centrais dos artigos foram bastante difusas, indicando o quão vasto é o campo de estudo acerca da sucessão familiar. Alguns artigos, trataram apenas do processo sucessório em si, enquanto outros, abordaram diferentes enfoques inerentes ao processo. As temáticas acerca de gênero, gestão, governança corporativa e profissionalização, foram 
identificados como temas mais recorrentes, além do processo sucessório propriamente dito. $\mathrm{O}$ Quadro 6, ratifica as temáticas abordadas.

Quadro 6. Temática central abordada nos artigos

\begin{tabular}{|c|c|}
\hline Temática central & Autores \\
\hline Características processo sucessório & (PETRY; NASCIMENTO, 2009) \\
\hline Ciclo de vida & (CANÇADO et al., 2013) \\
\hline Competências gerenciais & (NEPOMUCENO; SANTOS, 2009) \\
\hline Controller no processo sucessório & (LEAL; BOTINHA, 2013) \\
\hline Desafios Futuros & (BORGES et al., 2016) \\
\hline Dilemas éticos & (OLIVEIRA; DA SILVA, 2012) \\
\hline Diretrizes estratégicas & (OLIVEIRA; BERNARDON, 2008) \\
\hline Duelos/Conflitos & (TEIXEIRA; CARVALHAL, 2013; LEONE, 2008) \\
\hline Empreendedorismo & (BORGES et al., 2016) \\
\hline Empresa familiar & (PAIVA; OLIVEIRA; MELO, 2008) \\
\hline Estratégia & (ZILBER et al., 2010) \\
\hline Formação sucessor & (TESTON; FILIPPIM, 2016; JAMIL, DE SOUZA-SILVA, 2011) \\
\hline Gênero & $\begin{array}{l}\text { (ALBUQUERQUE; PEREIRA; OLIVEIRA, 2014; MACHADO; } \\
\text { WETZEL; RODRIGUES, 2008) }\end{array}$ \\
\hline Gestão & $\begin{array}{l}\text { (ANDRADE et al., 2017; KOGUT; FLECK, 2017; REMONDES; } \\
\text { SILVA, 2015; TOMEI; FERRARI, 2010) }\end{array}$ \\
\hline Governança corporativa & $\begin{array}{l}\text { (ROTH; TISSOT; GONÇALVES, 2017; CANÇADO et al., 2013; } \\
\text { VELLOSO; GRISCI, 2014; OLIVEIRA, ALBUQUERQUE; } \\
\text { PEREIRA, 2012; OLIVEIRA et al., 2011; OLIVEIRA BERTUCCI et } \\
\text { al., 2009) }\end{array}$ \\
\hline Maturidade & (DUARTE; OLIVEIRA, 2010) \\
\hline Mito & (PEREIRA et al., 2013) \\
\hline Mudança Organizacional & (SANTOS et al., 2015; PINTO; COUTO-DE-SOUZA, 2009) \\
\hline Padrões comportamentais & (LAIMER, TONIAL, 2014) \\
\hline Perfil empreendedor & (HOELTGEBAUM; SILVEIRA; DE CAMARGO, 2008) \\
\hline Práticas empreendedoras & (BORGES et al., 2015) \\
\hline Processo sucessório & $\begin{array}{l}\text { (SANTOS et al., 2017; OLIVEIRA et al., 2014; GONZALEZ et al. } \\
\text { 2011; FREIRE et al., 2010) }\end{array}$ \\
\hline Profissionalização & $\begin{array}{l}\text { (BELMONTE; FREITAS, 2013; OLIVEIRA, ALBUQUERQUE; } \\
\text { PEREIRA, 2012) }\end{array}$ \\
\hline Racionalidade & (OLIVEIRA; DA SILVA, 2012) \\
\hline Trajetória sucessores & (LEONE; LEONE, 2008) \\
\hline
\end{tabular}

Fonte: Elaborado pelos autores, 2017.

Por fim, o levantamento das palavras-chave identificou 136 palavras, com destaque para empresa e negócio familiar, como também sucessão e afins, ambos grupos de palavras apareceram 31 vezes. Inúmeras e diferentes palavras levam ao material desejado, estas servem de apoio, especialmente para pesquisas iniciais, como também para referências futuras.

As palavras-chave que mais apareceram nos 37 artigos analisados foram: empresa familiar (19) + empresas familiares (8) + negócio familiar (4), totalizando 31; sucessão (16) + processo sucessório (8) + sucessão familiar (4) + sucessão empresarial (3), também representando 31 vezes; governança (3) + governança corporativa (2), aparecendo em 5 artigos.
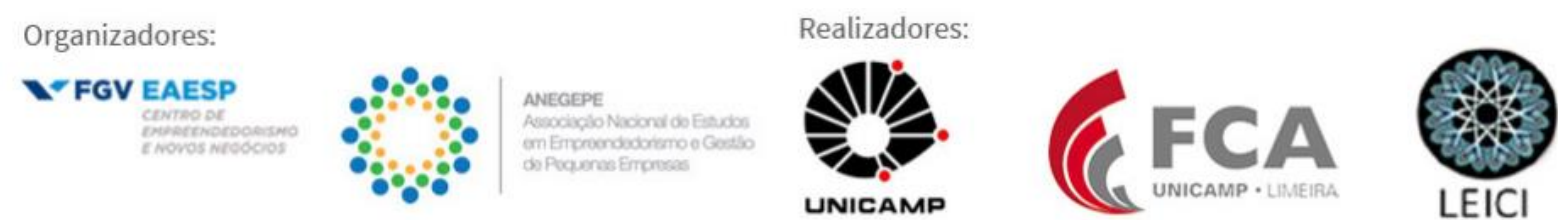


\section{Discussão e agenda de pesquisas}

Este tópico consiste em analisar e discutir os principais resultados integrando teses, dissertações e artigos, no que tange ao aspecto metodológico e as temáticas centrais. Visa ainda evidenciar as principais lacunas e de acordo com elas apresentar a proposta de uma agenda de pesquisa, tendo em vista ser essa uma das sugestões de SANTOS et al. (2017).

Em relação as características metodológicas, a abordagem qualitativa é predominante, totalizando entre teses, dissertações e artigos, 62 estudos. Já a abordagem quantitativa ou mista resulta em 8 estudos, sendo todos eles artigos. Neste sentido, evidencia-se a primeira lacuna, que é em relação ao tipo de abordagem.

Diversos estudos qualitativos apontam como sugestão de pesquisa futura a ampliação do campo de estudo ou ainda, a utilização de uma abordagem quantitativa (ROTH; TISSOT; GONÇALVES, 2017; FREITAS, 2015; FERRAZZA, 2010).

Quanto as temáticas centrais, confrontando as apresentadas no Quadro 3, referente à teses e dissertações com as do Quadro 6, alusivas aos artigos, encontramos 11 temáticas em comum, sendo elas: competências gerenciais; conflitos e duelos; desafios; formação do sucessor; gênero; gestão; governança; maturidade; mito fundador; processo sucessório; e profissionalização.

Como resultado geral, o processo sucessório em si, é o tema mais pesquisado, seguido por governança, gênero, gestão e profissionalização. O Quadro 7 evidencia os estudos e as respectivas temáticas abordadas como uma proposta de agenda de pesquisa. As principais lacunas e sugestões de estudos futuros observadas foram:

\section{Quadro 7: Principais lacunas e sugestões de pesquisas}

\begin{tabular}{|c|c|c|}
\hline Temática & Lacunas/Sugestões & Autores \\
\hline \multirow{3}{*}{$\begin{array}{l}\text { Processo } \\
\text { Sucessório }\end{array}$} & Ampliar estudos; planejamento; gênero & SANTOS et al., 2017 \\
\hline & Ampliar estudo & FERREIRA, 2015 \\
\hline & Gênero & OLIVEIRA et al., 2014 \\
\hline \multirow{3}{*}{ Governança } & Estudo quantitativo; Ampliar período de observação & $\begin{array}{ll}\text { ROTH; } & \text { TISSOT; } \\
\text { GONÇALVES, } 2017\end{array}$ \\
\hline & $\begin{array}{l}\text { Planejamento; tipo ideal de governança em cada } \\
\text { empresa }\end{array}$ & FREITAS, 2015 \\
\hline & Aprofundar as análises; governança & VELLOSO; GRISCI, 2014 \\
\hline \multirow[t]{2}{*}{ Gênero } & Ampliar discussão & $\begin{array}{l}\text { ALBUQUERQUE; PEREIRA; } \\
\text { OLIVEIRA, } 2014\end{array}$ \\
\hline & Sucessão feminina; supervalorização patriarcal & ELOI, 2014 \\
\hline \multirow{3}{*}{ Gestão } & Reaplicar estudo & ANDRADE et al., 2017 \\
\hline & Liderança institucional; reaplicar estudo & KOGUT; FLECK, 2017 \\
\hline & Conflito & COELHO, 2013 \\
\hline \multirow[b]{2}{*}{ Profissionalização } & Profissionalização gestão; survey & BELMONTE; FREITAS, 2013 \\
\hline & Propriedade; gestão & $\begin{array}{l}\text { OLIVEIRA; } \\
\text { ALBUQUERQUE; PEREIRA, } \\
2012\end{array}$ \\
\hline
\end{tabular}

Fonte: Elaborado pelos autores, 2017.

De forma breve, seguem as lacunas e sugestões dos artigos apresentados no Quadro7. O artigo de Santos et al. (2017) consiste em uma análise dos artigos nos periódicos nacionais
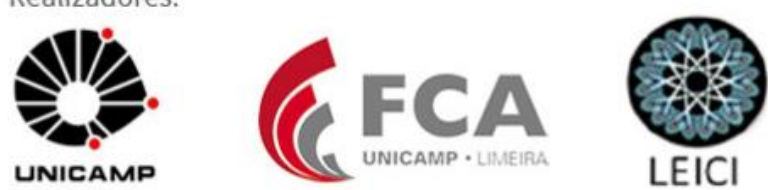
referente ao período de 2004 a 2015 e que tratam do processo de sucessão. Neste sentido, a sugestão de ampliação do estudo, ocorre em relação a aplicar uma análise em periódicos internacionais ou ainda, fazendo uma análise de ambos. Dentre as lacunas identificas nos artigos estudados a falta de planejamento para o processo sucessório resulta em sérios problemas, por isso, uma boa linha de pesquisa. Quanto as questões de gênero, há indícios de que o patriarcalismo ainda prevalece em muitas empresas.

No intuito de apresentar uma proposta de formação e desenvolvimento de carreira do sucessor, visando um processo sucessório exitoso, Ferreira (2015) utilizou em sua tese a perspectiva do modelo arco-íris de carreira. Assim, a proposta de ampliação do estudo decorre visando estudar também o "consórcio de primos" e ainda, ampliando o estudo para outras regiões no intuito de verificar se s resultados seriam idênticos ou divergentes.

Com o objetivo de compreender o processo sucessório em empresas familiares Oliveira et al., (2014) lançaram mão da perspectiva do conatus, segundo Bourdieu (1997). As análises versaram em quatro categorias: projeto; preparação; pertencimento e conflito. Destarte, e lacuna em relação ao gênero teria como intuito aferir se a repercussão dessa abordagem impactaria em diferenças significativas devido ao gênero do sucessor.

Implantar a governança corporativa nas empresas é eficaz para minimizar os conflitos advindos do processo de sucessão (ROTH; TISSOT; GONÇALVES, 2017). Os autores ainda apontam que quando o processo é bem planejado e acompanhado por uma boa gestão, pode tornar-se uma oportunidade para a organização. Considerando que a pesquisa foi aplicada em somente quatro empresas, o resultado é muito limitado, sendo a sugestão, ampliar a amostra, o período de observação, fazendo uso inclusive de um método quantitativo.

Buscando equilibrar a gestão dos interesses dos stakeholders como também os dos membros familiares, adotar práticas de governança pode reduzir riscos e propiciar maior estabilidade, resultando em vantagem competitiva quando há um planejamento de processo sucessório (FREITAS, 2015). Neste sentido, a proposta de estudo proposta por Freitas (2015) refere-se a pesquisar o impacto do planejamento da formação de herdeiros, assim como averiguar qual a estrutura de governança ideal para cada tipo de empresa.

Ainda acerca da governança Velloso e Grisci (2014) corroboram com Freitas (2015) quanto a eficácia da governança corporativa, porém, apontam que ainda há insegurança entre os membros familiares. Ainda assim, os resultados apontam que a governança corporativa pode fortalecer a empresa, possibilitando maior atratividade para a mesma. As propostas de pesquisa apresentadas por esses autores, são: aprofundar as análises, confrontando os fundadores com membros familiares que não atuam na gestão; e, confrontar a governança corporativa em empresas familiares e não familiares, avaliando os respectivos resultados.

No tocante à temática gênero, Albuquerque; Pereira e Oliveira (2014) abordam em seu artigo a problematização das questões acerca do gênero e como este, interfere no processo sucessório de uma organização. Tendo em vista que a pesquisa se limita a apenas uma organização e que o resultado indica que as mulheres desde muito cedo foram afastadas da gestão na organização, a proposta consiste em ampliar a discussão acerca do tema, visando compreender tal motivação.

Já Eloi (2014) em sua dissertação, preconiza identificar quais são os elementos do processo sucessório que permitem a mudança aparente e o discreto aumento da passagem do bastão para as mulheres. A organização, objeto de estudo está em fase de preparação de uma
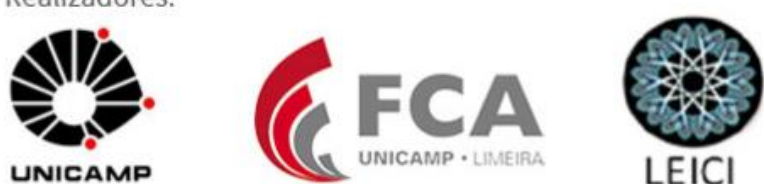
filha (herdeira) para que esta assuma o lugar do pai/fundador. No entanto, a condição de preparar a filha, neste caso, ocorre somente para garantir continuidade do controle patrimonial na família. Desta forma, cabe segundo Eloi (2014), investigar se o discreto aumento que ocorre está ou não relacionado com a cultura patriarcal e também se há relação do insucesso a partir da segunda geração com a supervalorização da tradição patriarcal.

Acerca da temática gestão, a validação de uma escala que mensura as práticas de estão em empresas familiares empreendedoras foi apresentada no estudo de Andrade et al. (2017). Teve uma abordagem quantitativa com análise fatorial exploratória, no entanto, a amostra não foi probabilística o que impossibilita generalizações, a proposta é de um novo estudo com uma amostra probabilista.

Com a intenção de averiguar qual dos tipos de gerenciamento cria mais valor para os acionistas Kogut e Fleck (2017) discutem as deficiências e vantagens da gestão profissional e da gestão familiar. Os resultados apontam que os investidores não são influenciados pelo tipo de gestão, mas sim, pelo tipo de liderança que há na organização, sendo assim, recomendam a ampliação do estudo, com foco na liderança institucional.

Ainda no tocante a gestão, Coelho (2013) identificou nas três empresas pesquisadas em sua dissertação que a gestão ou o tipo dela e um processo de profissionalização, pode não ter uma relação direta com o sucesso do processo sucessório, porém, por mais que as empresas apresentem indícios de gestão profissional, nenhuma delas possui um processo sucessório formalizado. A questão do conflito não foi abordada, deste modo, a proposta de estudo é sobre os conflitos em cada uma das dimensões do modelo tridimensional proposto por Gersik (1997).

A última temática proposta versa sobre a profissionalização. Belmonte e Freitas (2015) estudaram a profissionalização da gestão em duas empresas familiares. De acordo com os resultados, as empresas familiares que obtiverem um bom gerenciamento das variáveis: planejamento estratégico; processo sucessório; controle; gestão de pessoas; e gestão da cultura organizacional estão engajadas a ter uma gestão familiar profissional, aspecto que acarreta em benefícios para a mesma. Como o estudo pesquisou somente duas empresas, a proposta de pesquisa consiste na realização de um survey que verifique em nível regional, estadual ou nacional a profissionalização da gestão.

Oliveira, Albuquerque e Pereira (2012), estudam uma empresa de grande porte, investigando especialmente acerca da profissionalização da gestão. Defendem que o uso da "governança da empresa familiar" deve ser usado somente quando a empresa é de capital aberto, pois neste caso, de fato, os mecanismos "corporativos" podem ser implantados. A constituição da holding caracteriza a delimitação de propriedade e gestão. O estudo apresenta ainda proposições e indagações no intuito de contribuir para a elaboração de uma agenda de pesquisa. Sugere ainda averiguar o impacto de separar propriedade e gestão.

A última análise, foi em relação aos estudos que tratavam de revisão, dentre os 70 estudos analisados, 3 artigos tratam de revisão. Com uma amostra de 73 artigos nacionais Santos et al., (2017), analisaram: nomes autores; palavras-chave; tema central; teoria ou abordagem; tipo de pesquisa; perfil metodológico. Apresentam uma abordagem geral acerca de pesquisas futuras com base no resultado dos artigos analisados.

No estudo de Borges et al. (2016), a base foi composta por 73 artigos publicados em periódicos internacionais. A revisão consistiu na identificação das: principais temáticas;
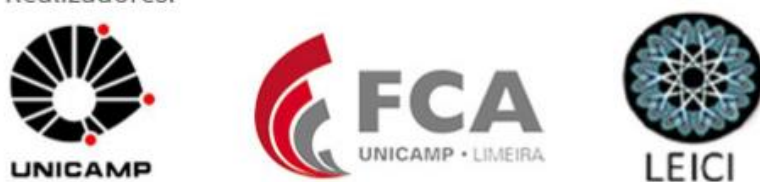
escolhas metodológicas; lacunas e direções futuras de pesquisa com enfoque em empreendedorismo familiar

O metaestudo realizado por Paiva, Oliveira e Melo (2008) contemplou a investigação de 83 artigos, todos advindos de publicações nos anais de todos os eventos organizados pela Anpad, compreendendo o período de 1997 até 2007. Os conteúdos forma categorizados mediante os critérios: distribuição anual e por evento; categorização temática; natureza da análise; setor econômico abordado; tipo de abordagem; principais técnicas de coleta e de análise de dados; base teórico-espistemológica; origem das bibliografias consultadas; tipos de materiais bibliográficos nacionais mais consultados e demografia de instituição de origem do primeiro autor.

\section{Considerações Finais}

Este estudo teve como objetivo analisar as publicações científicas brasileiras acerca da sucessão em empresas familiares, no período de 2007 a 2017. O estudo atingiu seus objetivos realizando uma revisão e análise completa das teses, dissertações e artigos que compreendem a temática. A busca das teses e dissertações foi realizada no portal CAPES no dia 13/10/217 e no BDTD - IBICT, em 16/10/2017, resultando em 3 teses e 30 dissertações. A busca dos artigos ocorreu nos periódicos apresentados no estudo de Santos et al. (2017) e resultou em 37 artigos

Respondendo à questão de pesquisa, as principais características foram evidenciadas em duas categorias, compreendendo: a) teses e dissertações, evidenciando: ano das publicações; instituições; metodologia; temática central; e principais palavras-chave; b) artigos, demonstrando: classificação Qualis dos periódicos; ano das publicações; principais autores; metodologia; temática central; e principais palavras-chave.

A discussão dos resultados contempla a análise integrada de teses, dissertações e artigos concernentes ao aspecto metodológico e temática central. Quanto o aspecto metodológico, identificou-se que há extrema carência de estudos quantitativos na área. Por meio das análises dos artigos acerca das temáticas, evidenciaram-se as principais lacunas e sugestões de pesquisas futuras, culminando com o Quadro 7 que contempla a agenda de pesquisa.

Uma limitação deste estudo, decorre da busca dos artigos apenas em periódicos nacionais, de maneira similar ao estudo de Santos et al. (2017). No entanto, como sugestão de pesquisa futura, cabe ampliar a busca para periódicos internacionais ou ainda, realizar buscas pelas bases de dados.

A principal contribuição, a partir dos estudos (teses, dissertações e artigos) é a elaboração de uma agenda de pesquisa que pode auxiliar os pesquisadores no direcionamento de suas pesquisas. Cabe ressaltar que não houve pretensão de esgotar o assunto com esta pesquisa e sim, incitar novas pesquisas a partir dos resultados encontrados. 


\section{Referências}

ALBUQUERQUE, Ana Luiza; PEREIRA, Rafael Diogo; OLIVEIRA, Janete Lara de. Sucessoras invisíveis: o impacto das questões de gênero nos processos de sucessão em empresas familiares. Gestão \& Planejamento-G\&P, v. 15, n. 2, p. 305-320, 2014.

ANDRADE, Daniela Meirelles et al. Fatores determinantes para empresas familiares empreendedoras. Gestão \& Planejamento-G\&P, v. 18, p. 330-348, 2017.

BARDIN, Laurence. Análise de conteúdo. São Paulo: Edições 70, 2010.

BELMONTE, Victor Antonio Barros; FREITAS, Wesley Ricardo Souza. Empresas familiares e a profissionalização da gestão: estudo de casos em empresas paulistas. Revista de Administração da UFSM, v. 6, n. 1, p. 71-90, 2013.

BORGES, Alex Fernando et al. Empreendedorismo em empresas familiares: a pesquisa atual e os desafios futuros. RAM, Rev. Adm. Mackenzie, São Paulo, v. 17, n. 2, p. 93-121, 2016.

BORGES, Alex Fernando; LESCURA, Carolina; OLIVEIRA, Janete Lara. O campo de pesquisas sobre empresas familiares no Brasil: análise da produção científica no período 1997-2009. Organizações \& Sociedade, v. 19, n. 61, 2012.

BORGES, Alex Fernando; LIMA, Juvêncio Braga de. A Construção do Processo de Sucessão Empreendedora em Empresas Familiares. In: encontro da ANPAD, 33. 2009. São Paulo, SP, 19 a 23 de maio de 2009.

BRITO, Mozar José de; SILVA, Sabrina Soares da; MUNIZ, Mayara Maria de Jesus. The meanings of the death of the founder: the constructionist approach. BAR-Brazilian Administration Review, v. 7, n. 3, p. 227-241, 2010.

CANÇADO, Vera Lucia et al. Ciclo de vida, sucessão e processo de governança em uma empresa familiar: um estudo de caso no Grupo Seculus. REAd-Revista Eletrônica de Administração, v. 75, n. 2, p. 485-516, 2013.

CHUA, Jess H.; CHRISMAN, James J.; SHARMA, Pramodita. Defining the family business by behavior. Entrepreneurship theory and practice, v. 23, n. 4, p. 19-39, 1999.

CHURCHILL, Neil C.; HATTEN, Kenneth J. Non-Market-Based Transfers of Wealth and Power: A Research Framework for Family Business. Family Business Review, v. 10, n. 1, p. 53-67, 1997.

COELHO, Haroldo Alves. Gestão profissional em empresas familiares: um estudo multicascos. 2013. 80 f. Dissertação (Mestrado Profissional em Administração) - Fundação Cultural Dr. Pedro Leopoldo - FPL, Pedro Leopoldo.

DE MASSIS, Alfredo; CHUA, Jess H.; CHRISMAN, James J. Factors preventing intra-family succession. Family Business Review, v. 21, n. 2, p. 183-199, 2008.

ELOI, Cristiany Bim Gurati. A passagem do bastão para herdeiras: o caso de uma empresa do ABC Paulista em fase de preparação para a sucessão familiar. 2014. 139 f. Dissertação

\section{Organizadores:}

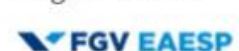

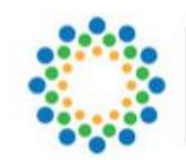
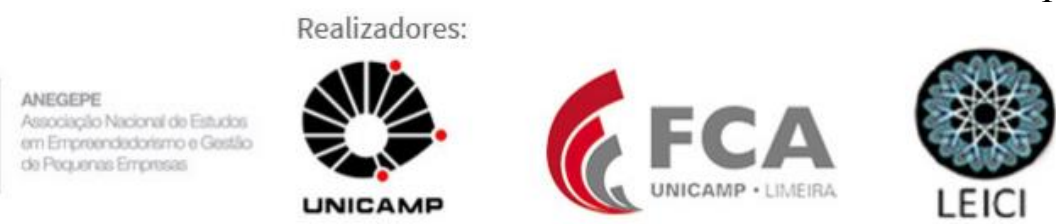
(Mestrado em Administração) - Faculdade de Administração e Economia da Universidade Metodista de São Paulo, São Bernardo do Campo.

FERRAZZA, Elisangela. A maturidade do processo de sucessão: um estudo multicaso em empresas familiares da serra gaúcha. 2010. 165 f. Dissertação (Mestrado em Administração) Universidade de Caxias do Sul, Caxias do Sul.

FERREIRA, Leandro de Oliveira. O processo sucessório da empresa familiar: proposta de formação e desenvolvimento de carreira do sucessor na perspectiva do modelo arco-íris de carreira. 2015. 256 f. Tese (Doutorado em Administração) - Faculdade de Gestão e Negócios - Universidade Metodista de Piracicaba, Piracicaba.

FREITAS, Livia Paulucci. A relação entre a implementação de mecanismos de governança corporativa e a evolução do processo sucessório em empresas de controle familiar: estudo de casos múltiplos. 2015. 100f. Dissertação (Mestrado em Administração) Universidade de São Paulo, São Paulo.

FRITZ, Roger. Empresa familiar: a sustentação da visão dos objetivos e da atuação empreendedora. São Paulo: Makron Books, 1993.

GERSICK, Kelin E. et al. De geração para geração. Rio de Janeiro: Elsevier, 2006.

GERSICK, Kelin E. et al. De geração para geração: ciclos de vida das empresas familiares. Rio de Janeiro: Negócios, 1997.

GIL, Antonio Carlos. Como elaborar projetos de pesquisa. 4. ed. São Paulo: Atlas, 2007.

HANDLER, Wendy C. Methodological issues and considerations in studying family businesses. Family business review, v. 2, n. 3, p. 257-276, 1989.

HARVEY, Michael; EVANS, Rodney. Life after succession in the family business: Is it really the end of problems? Family business review, v. 8, n. 1, p. 3-16, 1995.

KOGUT, Clarice Secches; FLECK, Denise. Professional versus family management in Brazilian fashion retail companies: exploring value-investors' perceptions. Cad. EBAPE.BR, Rio de Janeiro, v. 15, n. 3, p. 559-573, 2017.

LEONE, Nilda Maria de Clodoaldo Pinto Guerra. Os duelos (duetos) identificados por ocasião do processo sucessório. Revista Eletrônica de Estratégia \& Negócios, v. 1, n. 1, p. 104-122, 2008.

MEIRA TEIXEIRA, Rivanda; CARVALHAL, Felipe. Sucessão e conflitos em empresas familiares: estudo de casos múltiplos em empresas na cidade de Aracaju. Revista Alcance, v. 20, n. 3, p. 345-366, 2013.

MORRIS, Michael H. et al. Correlates of success in family business transitions. Journal of business venturing, v. 12, n. 5, p. 385-401, 1997. 
NETO, Adelino de Bortoli; MOREIRA, Jr Armando Lourenzo. Dificuldades para a realização da sucessão: um estudo em empresas familiares de pequeno porte. REGE Revista de Gestão, v. 8, n. $4,2010$.

OLIVEIRA, Djalma de Pinho Rebouças de. Empresa familiar. São Paulo: Atlas, 2006.

OLIVEIRA, Jante Lara de; ALBUQUERQUE, Ana. Luiza; PEREIRA, Rafael Diogo. Governança, sucessão e profissionalização em uma empresa familiar: (re)arranjando o lugar da família multigeracional. Revista Brasileira de Gestão de Negócios, v. 14, n. 43, p. 176$192,2012$.

OLIVEIRA, Márcia Freire de et al. Compreensão do processo sucessório sob a perspectiva do conatus segundo Bourdieu (1997): um estudo multicasos em pequenas empresas familiares de Uberlândia-MG. Economia \& Gestão, v. 14, n. 36, p. 57-84, 2014.

PAIVA, Kely César Martins, OLIVEIRA, Michelle Cristina de Souza; MELO, Marlene Catarina de Oliveira Lopes; DE; DE. Produção científica brasileira sobre empresa familiar um metaestudo de artigos publicados em anais de eventos da ANPAD no período de 1997 2007. RAM. Revista de Administração Mackenzie, v. 9, n. 6, p. 148-173, 2008.

PAPA, Adriana Cassia; LUZ, T. R. O papel do fundador na cultura de uma empresa familiar: um estudo de caso em João Monlevade-MG. Anais do Encontro da Associação Nacional de Pós-Graduação em Pesquisa e Administração, 2008.

PWC - PricewaterhouseCooperes. As empresas familiares no Brasil: pesquisa 2010. Disponível em: <http://www.pwc.com.br>. Acesso em: 19 ago. 2017.

RICHTER, Juliana. Planejamento sucessório de empresas familiares: uma análise de empresas de pequeno e médio porte sob a perspectiva do fundador. 2015 . $88 \mathrm{f}$. Dissertação (Mestrado em Administração) - Universidade do Vale do Rio dos Sinos, Porto Alegre.

ROTH, Leonardo; TISSOT, Maria Clara Heinz; GONÇALVES, Roberto Birch. Family Owned Business Succession and Governance: a multiple case study in Brazil. Revista de Ciências da Administração, v. 19, n. 48, p. 96-107, 2017.

SANTOS, Andreia Aparecida Pandolfi et al. Family succession: analysis of Brazilian writings from the period between 2004 and 2015. Revista Brasileira de Estratégia, v. 10, n. 1, p. 150, 2017.

SEBRAE NA (2013), "Sobrevivência das Empresas no Brasil”. Brasília, 2013.Disponível em: http://www.sebrae.com.br/Sebrae/Portal\%20Sebrae/Anexos/Sobrevivencia_das_empresas_no _Brasil=2013.pdf. Acesso em: 19 ago. 2017.

VENTER, Elmarie; BOSHOFF, Christo; MAAS, Gideon. The influence of successor-related factors on the succession process in small and medium-sized family businesses. Family Business Review, v. 18, n. 4, p. 283-303, 2005. 